\section{Enteral tube feeding}

\author{
BM Wireko, specialist registrar in \\ gastroenterology, Nottingham University \\ Hospitals; Tim Bowling, consultant in \\ gastroenterology and clinical nutrition, \\ Queen's Medical Centre Campus, \\ Nottingham University Hospitals NHS Trust
}

This article is aimed at ward-based clinicians dealing with the everyday issues of enteral tube feeding (ETF). It is therefore intended to be a brief description of the essential clinical information to allow for safe and good practice. The areas covered are:

- indications

- routes and delivery of feeding

- complications.

Ethics of nutritional support is another extremely important component and is covered in another article in this series.

\section{Definition}

ETF is the delivery of nutritionally complete feed directly into the stomach or small intestine via a tube.

\section{Indications}

ETF is indicated in any patient who cannot meet nutritional requirements by oral intake and who has a functioning and accessible gastrointestinal (GI) tract. It can be administered either into the stomach or directly into the small intestine (usually the jejunum). Table 1 shows examples of when enteral feeding is indicated.

\section{Routes}

The possible routes of administration are listed in Table 2.

\section{Methods of feeding}

\section{Nasogastric tubes}

Nasogastric tubes are recommended for patients who require tube feeding for no longer than four to six weeks. This approach is safe, cost-effective and less invasive than gastrostomy. There are two types of NGT:

1 Fine-bore tubes, designed for administration of feed. They are usually easy to insert and are safe, even in patients with oesophageal varices. They should not be inserted in patients with obstructive pathology in the nasopharynx or oesophagus or in those with basal skull fractures.

2 Wide-bore tubes (eg Ryles), designed for aspiration. They can cause oesophageal damage such as ulceration and stricture if left in for a prolonged period, and should not normally be used for feeding.

It is important that the position of the NGT is correctly checked and confirmed after insertion to reduce the risk of complications. The National Patient Safety

\section{Table 1. Indications for enteral feeding.}

Patients with a functioning stomach and/or intestine

- Impaired swallow (eg stroke, MND, PD)

- Altered level of consciousness making oral feeding impossible

- Ventilated patients

- Dysphagia with oropharyngeal/oesophageal obstruction (ie head and neck and oesophageal cancer)

- Gastric outlet obstruction: mechanical (tumour, pyloric stricture) or functional (stasis) (these situations will require jejunal feeding)

- Severe pancreatitis (gastric or jejunal)

To supplement inadequate oral intake

- Cystic fibrosis

- Hypercatabolic states (eg burn injury, decompensated liver disease)

- Facial injury

- HIV wasting

- Psychological/psychiatric reasons (eg anorexia nervosa)

MND = motor neurone disease; PD = Parkinson's disease

Table 2. Possible routes of enteral tube feeding.

Nasogastric tube

Nasojejunal tube

Gastrostomy

Jejunostomy
Agency (NPSA) recommends that the $\mathrm{pH}$ of aspirate (stomach contents) should be less or equal to 5.5. ${ }^{1} \mathrm{~A}$ more alkaline $\mathrm{pH}$ may indicate positioning in the bronchial tree. It should also be noted that gastric $\mathrm{pH}$ will be elevated by acid-suppressing medications; patients receiving these will require a chest $\mathrm{X}$-ray (CXR) to verify the NGT position. ${ }^{1}$ The NPSA also recommends that tube position should be checked before each administration of feed or medication. ${ }^{1}$ However, there has to be an element of pragmatism in this: clearly a repeat CXR - even repeated aspirate testing - is unrealistic every time a feed or medication is given.

The most commonly encountered problem with NGT is inadvertent removal, either at the hand of the patient or by accident (eg snagged on clothing, vomiting). If this is a recurring problem and feeding is still required, either 
percutaneous endoscopic gastrostomy (PEG) can be considered or a 'nasal loop' or bridle attached, thereby making accidental removal far less likely. In one study accidental removal was $18 \%$ and $63 \%$ for bridled and non-bridled tubes, respectively, with the bridled group more likely to meet their recommended nutritional requirements. ${ }^{2,3}$ Bridle systems are commercially available. Although their unit cost is relatively high, this is more than offset by the avoidance of repeated NGT placements with or without X-rays to verify placement. Other complications of NGT are given in Table 3 .

\section{Nasojejunal tubes}

Specifically designed self-propelling nasojejunal tubes (NJTs) (eg the Bengmark tube (Nutricia, Trowbridge, UK) or Tiger Tube $^{\mathrm{TM}}$ (Cook Medical Inc, IN, USA)) will spontaneously cross the pylorus in $70-80 \%$ of patients with normal gastroduodenal motility, especially with a concurrent intravenous bolus of metoclopramide. If the stomach is atonic, NJTs usually require endoscopic placement. The distal end must be placed beyond the duodenojejunal flexure or it will invariably pass retrogradely back into the stomach. There are other systems that can facilitate transpyloric passage (eg Cortrak (Corpak MedSystems, IL, USA)), with which an electromagnetic device on the end of the tube can be tracked by a bedside imaging system to help ensure correct placement. Plain abdominal X-ray is required to verify placement unless placed under screening.

NJT comes as single double or triple lumen. Double or triple lumen tubes are recommended for patients who require simultaneous gastric decompression and small bowel feeding. Complications of NJT are listed in Table 3.

\section{Gastrostomy}

A gastrostomy is usually preferred if tube feeding is likely to be required for longer than four to six weeks. It can be placed endoscopically (PEG), radiologically (RIG) or, occasionally, surgically. A number of different types of PEG/RIG tubes are available in terms of size (9-24 FG), internal fixator (flange, balloon) and material, including more cosmetically acceptable 'button' gastrostomies.

PEG insertion is usually straightforward. Although not a sterile procedure, antibiotic prophylaxis (cefuroxime $750 \mathrm{mg}$ or co-amoxiclav $1.2 \mathrm{~g}$ ) $30 \mathrm{~min}$ prior to the procedure is recommended. ${ }^{4}$ Table 4 lists the contraindications to PEG insertion. It should be noted that many of the 'relative contraindications' to endoscopic placement can be overcome if insertion is done under radiological guidance.

PEGs and RIGs can be easily removed, but care is required. If removed within two to three weeks of insertion a formal tract may not have formed, with consequent risk of spillage of gastric contents into the peri-

toneal cavity leading to peritonitis. This also means that it is not possible to re-insert a feeding tube down the same track as it will not find its way into the gastric lumen. Therefore if the PEG/RIG comes out in the first few weeks of insertion, the stoma site should be covered, antibiotic cover instituted and, if nutritional support is still required, an alternative route (eg NGT) used until the wound has healed.

Removal after two to three weeks presents little risk of peritonitis or sepsis. However, closure is rapid; if replacement is required, this must be done within four to six hours using a fresh PEG/RIG or, temporarily, a balloon gastrostomy or Foley catheter. Elective removal is usually undertaken endoscopically. Alternatively, the tube can be cut close to the skin allowing the internal fixator to pass spontaneously

Table 3. Complications of nasogastric and nasojejunal tube feeding (common complications in bold).

\begin{tabular}{|c|c|}
\hline Complications & Explanation \\
\hline \multirow[t]{2}{*}{ Removal by patient } & - $\quad$ Purposeful: consider patient withdrawal of consent \\
\hline & $\begin{array}{l}\text { Confused: may need re-siting or, if repeated removal, } \\
\text { consider nasal loop/bridle or alternative means of } \\
\text { nutritional support (eg PEG ) }\end{array}$ \\
\hline $\begin{array}{l}\text { Oesophageal ulceration } \\
\text { or strictures }\end{array}$ & Uncommon if fine-bore tubes used \\
\hline \multirow[t]{2}{*}{ Malposition } & $\begin{array}{l}\text { Malposition into lungs can lead to infection, effusion and } \\
\text { empyema }\end{array}$ \\
\hline & $\begin{array}{l}\text { Tube can occasionally be malpositioned intracranially; } \\
\text { correct verification of tube position should avoid } \\
\text { this }^{1}\end{array}$ \\
\hline \multirow[t]{3}{*}{ Aspiration } & $\begin{array}{l}\text { Minimised by feeding for no more than } 20 \mathrm{~h} / \text { day at an } \\
\text { elevation of at least } 30^{\circ}\end{array}$ \\
\hline & $\begin{array}{l}\text { Aspiration of gastric contents into the bronchial tree } \\
\text { occurs for most patients on intragastric feeding; } \\
\text { fortunately, clinical events are not so commonplace }\end{array}$ \\
\hline & $\begin{array}{l}\text { Patients need to be monitored for clinical signs of RTI } \\
\text { and treated appropriately with antibiotics if this occurs. } \\
\text { It may also be necessary to stop the intragastric } \\
\text { feeding and consider postpyloric feeding }\end{array}$ \\
\hline \multirow[t]{2}{*}{ Blockage } & $\begin{array}{l}\text { All types of enteral feeding tubes may become blocked, } \\
\text { with fine-bore tubes particularly at risk. Tubes should } \\
\text { be flushed with water before starting and after } \\
\text { completion of a feed, } 4-6 \text { hourly throughout feeding } \\
\text { and before and after medication, as residue can } \\
\text { quickly build up. If blocked, soda water or pancreatic } \\
\text { enzymes, which break down coagulated protein, } \\
\text { can be used }\end{array}$ \\
\hline & $\begin{array}{l}\text { - Acidic fizzy drinks, such as cola, can coagulate protein in } \\
\text { the tube and exacerbate the problem, and should } \\
\text { therefore not be used }\end{array}$ \\
\hline
\end{tabular}

$\mathrm{PEG}=$ percutaneous endoscopic gastrostomy; $\mathrm{RTI}=$ respiratory tract infection . 
Table 4. Contraindications to percutaneous endoscopic gastrostomy insertion.

\begin{tabular}{|c|c|}
\hline Absolute & Relative \\
\hline $\begin{array}{l}\text { - Inability to pass endoscope due to } \\
\text { obstructing pathology in oropharynx } \\
\text { or oesophagus* } \\
\text { - Obstructing gastric outflow pathology } \\
\text { - Significant ascites } \\
\text { - Gastric varices }\end{array}$ & $\begin{array}{l}\text { - Severe obesity (due to technical } \\
\text { - } \text { difficulties accessing the stomach)* } \\
\text { - } \text { Portal hypertension/ascites } \\
\text { - } \text { Active gastric ulceration/malignancy } \\
\text { - Gastroparesis } \\
\text { - Gastrectomy (total or partial)* } \\
\text { - Severe kyphoscoliosis (may be difficult to } \\
\text { - } \quad \text { Impaired respiratory reserve (eg MND) } \\
\text { - Current peritoneal dialysis }\end{array}$ \\
\hline
\end{tabular}

* may be achievable if performed under radiological guidance to locate stomach. MND = motor neuron disease through the GI tract. There are no reported incidents of obstruction (eg at the ileocaecal junction). This method is probably safe, provided that there is no suggestion of small intestinal pathology such as strictures.

\section{Jejunostomy}

PEGJs are 'extensions' that attach to a PEG and can be passed endoscopically beyond the duodenojejunal flexure. Endoscopic jejunostomy (PEJ) is similar to PEG but requires a direct puncture into the small intestine. Insertion techniques are not straightforward and, on the whole, there is probably no advantage of these over a surgically-placed jejunostomy for postpyloric feeding, except in a patient who is too unfit to have a general anaesthetic. Removal and complications of PEGJ/PEJ are similar to those for PEG (Table 5).

Surgical insertion. Surgical jejunostomies are most commonly needle catheter jejunostomies inserted subserosally to reduce the risk of leakage, but they tend to be fine bore and prone to block if poorly managed. Other tubes such as Foley catheters can be used, but are not recomin connecting with feeding equipment. Increasingly, jejunostomies are inserted peroperatively to allow for early postoperative feeding. Although complications can occur, the advantages of improved postoperative nutrition usually outweigh the risks. mended because of leakage and difficulties feeding can also cause GI problems such as diarrhoea, nausea and vomiting, reflux, and metabolic abnormalities such as refeeding syndrome and various electrolyte disturbances.

\section{Gastrointestinal problems}

Diarrhoea. Diarrhoea can be problematic and sometimes difficult to manage, with an incidence that can be as high as $60 \%$ in critical care. Luft et $a^{5}$ found an incidence of $18 \%$ among patients on medical and surgical wards receiving enteral nutrition compared with $6 \%$ in matched controls. The causes are multifactorial and include concomitant medication (especially antibiotics and laxatives) and contaminated feeds. Management should include:

- a review and rationalisation of medication

Feed can be administered as a bolus or continuously. Continuous feeding is usually over 16-18 hours, while bolus feeds are typically $100-500 \mathrm{ml}$ of feed over $15-60 \mathrm{~min}$ at 3-6 hour intervals. Bolus feeding into the stomach is more physiological. There is a perception that it predisposes to aspiration, diarrhoea, bloating and dumping syndrome compared with continuous feeding, but there is no clinical evidence to support this. With jejunal feeding, the loss of the stomach reservoir means patients with postpyloric tubes should be fed continuously.

\section{Other complications associated with enteral feeding}

In addition to complications associated with the tubes and their insertion, enteral
- stool cultures for Clostridium difficile and other infective organisms

- exclusion of other causes of diarrhoea.

Treatment should concentrate on symptomatic control with loperamide and codeine. Slowing down the feed rate and using low volume/high caloric content feeds, changing to a different mode of delivery (continuous, bolus, etc) or introducing fibre to the diet can sometimes be successful. Only in the most severe cases would consideration of parenteral feeding be appropriate.

Vomiting/aspiration/reflux. Both nasogastric and PEG feeding increase the risk of aspiration. Where possible, patients

\section{Key points}

Enteral tube feeding (ETF) should be managed by a multiprofessional team

ETF is required for patients with a functioning gastrointestinal tract unable to meet their nutritional requirements orally

ETF can be either intragastric or postpyloric

Nasogastric/nasojejunal tubes are preferred for short-term ( $<4$ weeks) and stomas for longer-term feeding

Enteral feeding is generally safe. Complications are quite frequent, but most are minor and easily managed

KEY WORDS: complications, delivery, indications, routes, stomas 
should be fed at an elevation of 30-45. Standard antiemetics and prokinetic agents can be effective. Alternative or additional management options include:

- alteration of feed delivery (change from bolus to continuous feeding)

- changing to a more energy dense diet with smaller volumes delivering equivalent calories

- considering postpyloric feeding because of the lower risk of aspiration.

\section{Metabolic complications}

A deficiency or excess of any macro- or micronutrient can potentially be caused by enteral feeding. Monitoring of patients is essential.

Table 5. Complications of feeding stomas (percutaneous endoscopic gastrostomy (PEG) and endoscopic jejunostomy (PEGJ and PEJ)) (common complications in bold).

\section{Early}

- Pain: common within first $24 \mathrm{~h}$. If severe, exclude peritonitis/tube displacement into anterior abdominal wall

- Haemorrhage: unusual if clotting screen within normal limits. Malnutrition can lead to vitamin $\mathrm{K}$ deficiency, so PT/INR should always be checked prior to procedure

- Peritonitis

- Pneumoperitoneum: there will always be some free air after PEG insertion

- Gastrocolic fistula due to interposition of colon between anterior abdominal wall and stomach

Late

- Stoma infection: usually resolves with appropriate antibiotics (eg flucloxacillin) and proper stoma care. Not usually necessary to remove PEG or stop feeding unless severe ulceration or wound breakdown

- Tube blockage: minimised if flushed with water before and after each feed/medication (see NGT blockage in Table 3)

- Aspiration: minimised by feeding for no more than $20 \mathrm{~h} /$ day at an elevation of at least $30^{\circ}$

- Buried bumper: migration of internal fixator into gastric/anterior abdominal wall leading to tube blockage, usually requiring surgery to remove

- Tumour tract seeding: a few case reports of PEGs inserted in oesophageal or oropharyn geal tumours developing neoplastic seeding in stoma tracks. Where the PEG is inserted as part of palliative care, this is unlikely to be of relevance in the patient's lifetime

- Overgranulation: can occur at stoma site and bleed/become painful. Treated with steroid cream or silver nitrate

- Mortality: 30 -day mortality of $6 \%$ reported in NCEPOD $2004,{ }^{8}$ but $3.3-18.2 \%$ in other recent studies. ${ }^{9}$ This can be reduced with better patient selection

INR = international normalised ratio; NCEPOD; National Confidential Enquiry into Patient Outcome and Death; NGT = nasogastric tube; $\mathrm{PT}=$ prothrombin time. monitoring and correction of electrolyte imbalance. ${ }^{7}$

\section{Conclusions}

ETF is usually a relatively straightforward method of nutritional support and should be facilitated by a multiprofessional team. However, the attending healthcare professionals need to be aware of the problems and complications that can arise and how to deal with them.

\section{References}

1 National Patient Safety Agency. Advice to the NHS on reducing harm caused by the misplacement of nasogastric feeding tubes. London: NPSA, 2005. www.nrls.npsa.nhs.uk/ resources/?entryid $45=59794$

2 Seder CW, Stockdale W, Hale L, Janczyk RJ. Nasal bridling decreases feeding tube dislodgment and may increase caloric intake in the surgical intensive care unit: a randomized, controlled trial. Crit Care Med 2010;38:797-801.

3 Brandt CP, Mittendorf EA. Endoscopic placement of nasojejunal feeding tubes in ICU patients. Surg Endosc 1999;13:1211-4.

4 Allison MC, Sandoe JA, Tighe R et al; Endoscopy Committee of the British Society of Gastroenterology. Antibiotic prophylaxis in gastrointestinal endoscopy. Gut 2009;58:869-80.

5 Luft VC, Beghetto MG, de Mello ED, Polancyk CA. Role of enteral nutrition in the incidence of diarrhoea among hospitalized adult patients. Nutrition 2008;24: 528-35.

6 Boateng AA, Sriram K, Meguid MM, Crook M. Refeeding syndrome: treatment considerations based on collective analysis of literature case reports. Nutrition 2010;26:156-67.

7 National Institute for Clinical Excellence. Nutritional support in adults. London: NICE, 2006. www.nice.org.uk/nicemedia/live/ 10978/29981/29981.pdf

8 National Confidential Enquiry into Patient Outcome and Death (NCEPOD). Scoping our practice. London: NCEPOD, 2004. www.ncepod.org.uk/2004sop.htm

9 Galaski A, Peng WW, Ellis M et al. Gastrostomy tube placement by radiological versus endoscopic methods in an acute care setting: a retrospective review of frequency, indications, complications and outcomes. Can J Gastroenterol 2009;23:109-14.

Address for correspondence:

Dr T Bowling, Queen's Medical Centre

Campus, Nottingham University Hospitals NHS Trust, Nottingham NG7 2UH.

Email: tim.bowling@nuh.nhs.uk 